\title{
Functional Fecal Incontinence in Children
}

\author{
Marloes E.J. Bongers Marc A. Benninga \\ Department of Pediatric Gastroenterology and Nutrition, Emma Children's Hospital, Academic Medical Centre, \\ Amsterdam, The Netherlands
}

\author{
Key Words \\ Functional fecal incontinence $\cdot$ Encopresis $\cdot$ Constipation, \\ pediatric
}

\begin{abstract}
Fecal incontinence is defined as the passage of stools in an inappropriate place. This frustrating symptom is a source of considerable distress and embarrassment for the child and his/her family. Pediatric fecal incontinence can be divided into 2 main categories: (1) organic fecal incontinence, e.g., resulting from anorectal malformations or neurogenic abnormalities, and (2) functional fecal incontinence. This review will only address functional fecal incontinence in children, and the definition, epidemiology, pathophysiology and recent updates on the clinical and diagnostic aspects of functional fecal incontinence will be discussed.
\end{abstract}

Copyright $\odot 2007$ Nestec Ltd., Vevey/S. Karger AG, Basel

\section{Definition}

In the past the terms encopresis and soiling were interchangeably used to describe functional fecal incontinence. The difference in terminology as used by many caregivers is the quantity of feces lost [1]. Encopresis is defined as repeated voluntary or involuntary passage of normal stools into inappropriate places (e.g. clothes, floor) after the age of 4 years (or equivalent developmental level) without any organic cause [2], whereas soiling is the involuntary leakage of small amounts of stools, result-

\section{KARGER \\ Fax +4161306 1234 \\ E-Mail karger@karger.ch}

www.karger.com (c) 2007 Nestec Ltd., Vevey/S. Karger AG, Basel

0517-8606/07/0652-0081\$23.50/0

Accessible online at:

www.karger.com/ane ing in stained underwear [1]. Pediatricians worldwide use the term encopresis in different contexts. For example pediatricians in the USA often view encopresis as an abnormal aggression regulation in children, while for pediatricians in Europe and Australia encopresis is strongly associated with constipation.

Fecal incontinence is the key feature of childhood constipation [3]. It is a well-recognized symptom and easy to score by the parents. Moreover, in our outpatient clinic we use the frequency and amount of feces lost in the underwear as an objective marker of the severity of constipation and the effectiveness of treatment. Therefore it is surprising that fecal incontinence was not included in the definitions of functional constipation (FC) and functional fecal retention in the Rome II criteria, as defined in 1999 [4]. Two recent studies determined the applicability of the Rome II criteria in clinical practice $[3,5]$. Voskuijl et al. [3] evaluated 130 patients with complaints of constipation and/or fecal incontinence. They found that $16 \%$ of the patients with constipation were not recognized as such by the Rome II criteria [3]. Loening-Baucke [5] studied 213 children presenting with fecal incontinence to assess whether these children fulfilled the Rome II criteria for functional fecal retention. Only $41 \%$ of these children fitted these criteria, while $85 \%$ had signs of fecal retention in their medical history or on physical examination. Both studies concluded that the Rome II criteria were too restrictive and excluded many patients with constipation. Based on the recommendations of these studies fecal incontinence was incorporated as one of the criteria of FC in the Rome III criteria. In these criteria, the terms en- 
Table 1. Rome III criteria

1 Functional constipation: in infants up to 4 years, an at least 1-month history of at least 2 of the following:

Defecation frequency $\leq 2$ times/week

Fecal incontinence $\geq 1$ times/week after the acquisition of toileting skills

History of excessive stool retention

History of painful or hard bowel movements

Presence of a large mass in the rectum

History of large-diameter stools that may obstruct the toilet No evidence of structural, endocrine, or metabolic disease

2 Functional non-retentive fecal incontinence: in a child with a developmental age of at least 4 years, an at least 2-month history before diagnosis of:

Defecation into places inappropriate to the social context $\geq 1$ times/month

No evidence of an inflammatory, anatomic, metabolic, or neoplastic process that explains the subject's symptoms No evidence of fecal retention copresis and soiling have been replaced by the more neutral term functional fecal incontinence. Functional fecal incontinence can be further subdivided into FC-associated fecal incontinence and functional non-retentive fecal incontinence (FNRFI). The Rome III criteria for FC and FNRFI are shown in table 1 [6].

\section{Epidemiology}

A recent systematic review reported that the worldwide prevalence of childhood constipation in the general population ranges from 0.7 to $29.6 \%$ (median 8.9; interquartile range 5.3-17.4) [7]. Most studies report similar prevalence rates for boys and girls [7]. Only two epidemiological studies were identified addressing the presence of fecal incontinence in constipated children. In 1,975 Greek children aged 2-14 years significantly more fecal incontinence was found in constipated children compared to controls (25 vs. $0.4 \%$ ) [8]. On the contrary, in 319 Brazilian children aged 8-10 years no difference in fecal incontinence between constipated children and non-constipated children was found (19 vs. 14\%) [9]. No plausible explanation was given for the low frequency of fecal incontinence in the constipated children and the high frequency in the non-constipated children.

Epidemiological studies on the prevalence of fecal incontinence are scarce and generally outdated. In 1966,
Bellman [2] reported that the prevalence of fecal incontinence among children over 4 years of age was $1.3 \%$. The prevalence among 7 - to 8 -year-olds was $2.3 \%$ for boys and $1.3 \%$ for girls and among 10 - to 12 -year-olds 1.3 and $0.3 \%$, respectively $[2,10]$. A male predominance was present with a male:female ratio ranging from $3: 1$ to $6: 1[2,11$, 12]. A recent population-based study on the prevalence of fecal incontinence collected information on fecal incontinence in 13,111 children aged 5-6 years and 9,780 children aged 11-12 years [13]. The overall prevalence of fecal incontinence was $3.0 \%$. The presence of fecal incontinence was more frequently found among 5- to 6-yearolds than 11- to 12 -year-olds (4.1 vs. 1.6\%) and was found more often in boys than girls (3.7 vs. 2.4\%) [13].

The fact that none of the published epidemiological studies on fecal incontinence made a distinction between FC and FNRFI is a clear shortcoming. In future studies, the Rome III criteria should be used in large populationbased studies to gain more insight into differences in prevalence between these two clinical entities.

\section{Pathophysiology}

The onset of childhood constipation is usually in the first 4 years of life. Withholding behavior plays an important role in the development and/or persistence of constipation. The time of toilet training is thought to be a critical period when constipation may occur as a consequence of the struggle between the child and his/her parents [14]. Interestingly, Borowitz et al. [15] found no association between timing, style or techniques used for toilet training and the development of early childhood constipation. Several other reasons may lead to stool withholding behavior in children: (1) previous experience with painful or hard stools; (2) anal fissures; (3) lack of time for regular toileting, and (4) resistance to use toilets other than the child's own [15].

Retained stools become progressively more difficult to evacuate, leading to a vicious circle in which the rectum is increasingly distended by abnormally firm and large stools [1]. Chronic distention of the rectum subsequently leads to overflow incontinence. Long-term fecal impaction eventually might lead to a dilated rectum with decreased rectal tone and decreased rectal contractility contributing to delayed evacuation of feces [16]. Finally, impaired rectal function, rather than withholding stools, might lead to persistent infrequent defecation. Voskuijl et al. [17] reported higher distensibility (compliance) of the rectum in constipated children compared to healthy chil- 
dren. This finding suggests that the rectum is stretched and larger stool volumes are needed to trigger rectal sensation, such as the urge to defecate. Rectal sensation was not found to be disturbed in constipated children and children with FNRFI [17]. Although disturbed compliance is present in the majority of children with long-term constipation, the clinical relevance has not yet been investigated. In children with FNRFI, rectal compliance did not differ compared to healthy children, underlining the fact that this is a separate clinical entity $[17,18]$.

Fecal incontinence is often associated with behavioral problems. Dated psychiatric literature viewed children with fecal incontinence as having severe behavioral problems, characterized by passive/aggressive personality styles $[2,19,20]$. It has been suggested that these behavioral problems are the cause of fecal incontinence and that therefore children with fecal incontinence need to be treated in a psychiatric setting [19]. Later, Gabel et al. [21] found that children with fecal incontinence indeed have a higher incidence of behavioral problems compared to a normative sample, but not to the degree usually found in children referred to mental health services. Two recent epidemiological studies both found higher rates of emotional and behavioral problems in children with fecal incontinence compared to those without fecal incontinence $[13,22]$. Children with frequent episodes of incontinence (once a week or more) are more likely to have these problems than those who experience fecal incontinence occasionally (less than once a week) [22]. However, these studies do not answer the question whether psychological problems are a cause or a consequence of fecal incontinence.

Several studies have assessed behavioral problems in children with fecal incontinence in relation to constipation before and after treatment. Levine et al. [23] found that children with fecal incontinence were more socially withdrawn and had affective changes when compared to a control group. Relief of fecal incontinence after treatment was associated with a generalized improvement in behavioral profiles. Similarly, Young [24] found a decrease in behavioral problems and an improvement in the social competence of children with successful treatment of fecal incontinence.

One study assessed behavioral profiles in children with FNRFI [25]. Initially abnormal behavioral scores were observed in $35 \%$ of these children. Successful treatment was associated with an improvement in behavioral scores. These three studies support the idea that fecal incontinence plays an etiological role in the occurrence and maintenance of behavioral problems and cannot be pri- marily classified as a psychiatric disorder. This underscores the assumption that the initial treatment of children with fecal incontinence can be made in a pediatric clinic.

\section{Clinical Presentation}

Fecal incontinence is a particularly embarrassing and distressing condition with significant medical, social and economic implications. In the majority of children, a thorough clinical history and physical examination are sufficient to differentiate between fecal incontinence due to FC and FNRFI. The following case reports, describing 2 patients from our outpatient clinic, illustrate the most important clinical differences between FC and FNRFI.

\section{Case Report 1}

An 8-year-old girl with fecal incontinence was referred by a general pediatrician to our outpatient clinic. Meconium passed within $24 \mathrm{~h}$ after birth and there were no defecation problems during infancy or the toddler period. At the age of 3 years she was fully toilet trained, but when she started school at the age of 4 years she stopped going to the toilet to defecate. At the time of presentation at our outpatient clinic, she experienced fecal incontinence occurring 2-3 times daily, occasionally even at night. Once every 2 weeks she produced a large amount of feces that clogged the toilet. Stool consistency was hard. Frequently she complained of abdominal pain and poor appetite, both clearly related to her defecation pattern. Whenever she felt the urge to defecate, she crossed her legs to retain stool. Treatment with lactulose ( $15 \mathrm{ml} /$ day) showed no improvement. Abdominal examination was without abnormalities, but rectal examination showed perianal feces. Upon rectal digital examination a large fecal mass was found.

\section{Case Report 2}

A general physician referred an 8-year-old boy with fecal incontinence to our outpatient clinic. Meconium passage was within $48 \mathrm{~h}$ after birth. At the age of 3 he was fully toilet trained during the daytime, but from the age of 5 he suffered from frequent episodes of fecal incontinence without a clear cause. Despite normal defecation frequency on the toilet he had received various laxatives, including lactulose and polyethylene glycol 3350. However, these laxative treatment regimens resulted in a strong increase, rather than a decrease in the fecal incontinence episodes. After discontinuation of his laxative treatment his defecation frequency remained daily and stool consistency was normal. Nevertheless, no change was observed in the occurrence of the episodes of fecal incontinence. In contrast to children with severe chronic constipation who lose stool several times per day, in our patient with FNRFI fecal incontinence always happened once a day after school while playing with friends. Frequently he postponed a visit to the toilet when he felt the urge to defecate. He had a normal appetite and no complaints of abdominal pain. Furthermore he suffered from urinary incontinence during the night. Abdominal and rectal examination revealed no signs of fecal retention. 


\section{Clinical Symptoms}

Fecal incontinence is the result of severe fecal impaction in approximately $85 \%$ of constipated children [3]. In accordance with the clinical presentation of our first patient, children with FC present with a combination of low defecation frequency, passage of large amounts of stools, hard stools, fecal incontinence and retentive posturing. Infrequent defecation often results in intermittent passage of large stools. Increased episodes of fecal incontinence, abdominal pain and poor appetite often precede the passage of large stools. After defecation these symptoms diminish immediately [26]. Fecal incontinence is often the consequence of rectal impaction resulting in overflow incontinence during the daytime, and in severe cases even at night. As described in our patient, the presence of a rectal scybalum upon abdominal and/or rectal digital examination is found in approximately $40-80 \%$ of constipated children $[5,27]$. In children with fecal incontinence rectal examination provides valuable information, as fecal retention can be limited to the rectum and thus remains undetected by abdominal examination. Two studies showed that in $8-14 \%$ of the children, the presence of fecal retention detected upon rectal examination resulted in the recognition of constipation in these children $[3,5]$.

In contrast, no signs of constipation were present in the 8-year-old boy with fecal incontinence who visited our clinic. A normal defecation frequency in combination with normal stool consistency, no passage of large amounts of stools and no fecal impaction upon physical examination confirm the diagnosis of FNRFI. It is well known that in children with FNRFI, as our patient, the number of fecal incontinence episodes increases instead of decreases on a regimen of laxatives. In these children, laxatives are contraindicated as they already have regular passage of normal stools. Nighttime fecal incontinence is rarely found in children with FNRFI (12\%) compared with constipated children (30\%) [28]. On the contrary, the frequency of daytime and nighttime urinary incontinence is higher in children with FNRFI (40-45\%) compared with constipated children (25-29\%) [29, 30].

\section{Diagnostic Work-Up}

\section{Medical History and Physical Examination}

The cornerstones for a diagnosis of FC and FNRFI are careful medical history and complete physical examination. The medical history should include questions about the child's bowel pattern from birth up to the present. Information about the age at onset of bowel problems, defecation frequency, stool consistency and size, occurrence of rectal blood loss, pain during defecation, passage of large amount of stools and retentive posturing is of major importance. The frequency of fecal incontinence, time (daytime and/or nighttime) and situation of occurrence (while playing outside, watching TV, or at the computer) need to be elicited. Accompanying symptoms such as abdominal pain, poor appetite and urinary incontinence should be assessed. Dietary history and the previously applied treatment strategies should also be determined. General information about growth, use of medication and neuromuscular development need to be obtained. Finally, information is essential on psychological or behavioral problems and family life events, such as birth of siblings, divorce of parents, death of a family member, and sexual abuse.

Complete physical and neurological examination should be performed in all children with defecation disorders [26]. Abdominal examination gives valuable information concerning the accumulation of gas or feces. Perianal inspection provides information about the position of the anus, perianal feces, redness, dermatitis, eczema, fissures, hemorrhoids, and scars. It is important to consider the possibility of sexual abuse if anal fissures and scars are found upon examination without evidence of a medical cause for these abnormalities. These anal findings are reported to be significantly more present in children with a history of anal sexual abuse [31,32]. Anorectal digital examination assesses perianal sensation, anal tone, size of the rectum, amount and consistency of stool in the rectum, voluntary contraction and relaxation of the anal sphincter, and the presence of an anocutaneous reflex (anal wink).

\section{Abdominal Radiograph and Colonic Transit Time}

In general practice, a plain abdominal radiograph is frequently used to visualize fecal loading in children with signs of constipation and/or fecal incontinence. However, conflicting data exist concerning the value of a plain abdominal radiograph in diagnosing constipation. A recent systematic review assessed the evidence from controlled studies concerning the association between scoring fecal loading on an abdominal radiograph and clinical signs and symptoms in children [33]. Only two high-quality studies have been identified. Based on these studies, it was concluded that a radiographic diagnosis of constipation occurs almost as often in clinically constipated as in clinically non-constipated children [33]. 
Additional use of radio-opaque markers in order to assess colonic transit time (CTT) is thought to obtain more valuable information about colorectal motor function than a plain abdominal radiograph. With the Bouchoucha method, patients ingest daily a capsule containing 10 markers over 6 consecutive days and on day 7 a single radiograph is obtained to calculate CTT [34]. With this technique both the overall colonic transit and segmental transit can be determined to distinguish different transit patterns: (1) normal CTT = normal transit through all colonic segments; (2) outlet obstruction = delayed transit through the anorectal region, and (3) slow transit constipation $=$ prolonged transit through the entire colon [26]. In approximately $50 \%$ of constipated children CTT is delayed [35-37]. In the majority of these children the delay of transit is found in the anorectal region [35]. Severe symptoms of constipation, as recorded by a child and/or the parents in a bowel dairy, are found to correlate strongly with prolonged CTT [35]. Moreover, self-reported symptoms in a bowel diary have been shown to correspond with the actual bowel habit of the child [38], thus emphasizing that an adequate inventory of clinical symptoms makes assessment of CTT superfluous. On the contrary, the marker test has proven useful in differentiating between children with constipation and children with FNRFI. Ninety percent of children with FNRFI have normal CTT [36]. Normal CTT in combination with a normal defecation pattern without a fecal mass on physical examination confirms the diagnosis of FNRFI.

\section{Magnetic Resonance Imaging of the Spinal Cord}

If neurological abnormalities are present on physical examination, an underlying closed spinal dysraphism, such as intradural lipoma, filar lipoma, dermal sinus and tight filum terminale, needs to be excluded [39]. Alarming neurological signs include motor and sensory dysfunction of the lower extremities and abnormal reflexes, or abnormal anorectal sensation and anocutaneous reflex (anal wink) [39, 40]. In children presenting with these abnormalities, magnetic resonance imaging of the spinal cord is required. In a recent study magnetic resonance imaging revealed spinal cord abnormalities in $9 \%$ of children with intractable constipation. After surgical repair, constipation resolved in $86 \%$ of these children [40]. This was a retrospective study of severely constipated patients not responding to aggressive clean-out regiments, which of course limits interpretation of these results. In the future, prospective studies in constipated children are necessary to further unravel possible underlying spinal cord abnormalities.

Functional Fecal Incontinence in Children

\section{Anorectal Manometry and Barostat}

Several techniques can be used to assess anorectal function. Anorectal manometry measures pressures in the anorectal region and is useful to assess sphincter function and contraction patterns. In constipated children anorectal manometry can be performed to assess the recto-anal inhibition reflex. The presence of this reflex excludes Hirschsprung's disease. In practice, performing such measurements in infants requires expertise as interpretation is often hampered by crying and movements of the infants. Furthermore, rectal suction biopsy is the most accurate test to diagnose Hirschsprung's disease, making this preferable to anorectal manometry [41].

Evaluating contraction patterns with anorectal manometry, it has been shown that approximately $50-60 \%$ of children with constipation and fecal incontinence present with abnormal defecation dynamics, e.g. inability to relax the external anal sphincter during defecation $[25,42,43]$. Normalization of defecation dynamics by biofeedback training was unrelated, however, to successful clinical outcome, suggesting that abnormal defecation dynamics are not an important pathophysiological feature in these children $[25,42]$.

In several studies using anorectal manometry, disturbed rectal sensitivity is demonstrated in a substantial proportion of children with constipation and fecal incontinence $[44,45]$. Measurement of visceral sensation via volume-controlled distention, like manometry, is known to be influenced by variability in compliance and the size of hollow organs [46]. Rectal barostat studies showed that rather than impaired sensitivity, increased compliance is the most prominent feature in patients with FC [17]. The clinical implication of this finding still needs to be unraveled. Thus, barostat studies in constipated children are still restricted to experienced groups. In children with FNRFI both compliance and rectal sensitivity are normal.

In conclusion, there is no indication for routinely performing anorectal manometry or barostat in children with constipation and fecal incontinence.

\section{Treatment}

The backbone of treatment of FC consists of education of the child and parents, behavioral modifications and laxative therapy [47]. An extensive overview of the multimodal treatment approach for childhood constipation is given elsewhere in this issue.

Ann Nestlé [Engl] 2007;65:81-88 
Derived from the treatment approach for constipated children, children with FNRFI are conventionally treated with education, behavioral modification (consisting of toilet training 3 times daily after meals) and keeping a bowel dairy [48]. A non-accusatory gentle approach is needed and therefore a reward system is useful. Laxatives are contraindicated in these children, as they already have a normal defecation frequency [29]. Other medical treatment options such as loperamide have been suggested, but its efficacy for the treatment of FNRFI needs to be studied further [49]. There is no evidence that biofeedback training adds any benefit to conventional treatment in the management of FNRFI in children [25]. No data exist on the role of psychological therapy for FNRFI. In future, well-designed randomized controlled trials to determine other treatment options of FNRFI are needed [25].

\section{Follow-Up}

Several studies have assessed the long-term follow-up of constipated children. Staiano et al. [50] followed 62 children for a period of 5 years. In half of the constipated children symptoms persisted during this follow-up period, meaning that they still experienced less than 4 bowel movements per week. Interestingly, the frequency of fecal incontinence decreased significantly regardless of constipation outcome. Another study with a median follow-up period of 4 years found that $66 \%$ of 137 constipated children were cured, although no clear definition of constipation was given [51]. Fecal incontinence at the time of presentation was not associated with a worse outcome at follow-up. A third follow-up study by Van Ginkel et al. [52] assessed follow-up in 403 constipated children. Success was defined as a defecation frequency of 3 or more times per week with less than 2 episodes of fecal incontinence for a period of 4 weeks. The cumulative percentage of successfully treated children during a total follow-up time of 8 years was $80 \%$, while $60 \%$ was already achieved at the 1-year follow-up. At least one relapse occurred in $50 \%$ of the children within the first 5 years after initial treatment success. Symptoms of constipation persisted into young adulthood in one third of all patients. In contrast to the previously mentioned study, successful outcome was higher in children without fecal incontinence at the time of presentation [52].

These findings show that in the majority of children with constipation, with or without fecal incontinence, the long-term prognosis is favorable. On the other hand, the general belief that children with constipation 'just grow out of it' with the onset of puberty has been refuted. Symptoms may even persist beyond 18 years of age. Chronic symptoms of constipation in children are associated with a lower quality of life [53]. Children themselves reported a lower quality of life, mainly due to impaired physical ability. Parents reported an even lower quality of life than their children, which was probable impacted by the duration of their child's symptoms and by family members with similar symptoms [53]. Not only in constipated children, but in all children with functional defecation disorders as defined by the Rome II criteria, a lower quality of life is found in comparison to healthy controls [54]. Practitioners need to be aware of the impact of these disorders on the child and the high level of concern of their parents during the treatment of these children.

Recently, a small study explored the relationship between functional childhood constipation and functional gastrointestinal disorders, such as constipation and irritable bowel syndrome, in adulthood [55]. A history of childhood constipation appeared to be a predictor of irritable bowel syndrome in adulthood. This study followed only 20 patients into adulthood, so prospective follow-up studies with larger samples should further investigate the outcome of childhood constipation. Follow-up of constipated children is important as relapse after successful treatment and persistence of symptoms into adulthood are not uncommon.

\section{Conclusion}

Functional fecal incontinence in children is generally the result of functional constipation. In clinical practice, the differentiation between functional constipation and functional non-retentive fecal incontinence in children presenting with fecal incontinence is essential as these two entities require different treatment strategies. A thorough clinical history and physical examination are the most important pillars to discriminate between these two entities. In future, well-designed studies are needed to gain more insight into the prevalence, pathophysiology and long-term outcome of pediatric functional gastrointestinal disorders. The use of the recently defined Rome III criteria in future studies may hopefully facilitate an international comparison of results and stimulate international collaboration in this field. 


\section{Key Messages}

(1) Functional fecal incontinence in children needs to be subdivided into constipation-associated fecal incontinence and functional non-retentive fecal incontinence, as defined by the Rome III criteria for childhood functional gastrointestinal disorders.

(2) In clinical practice, distinctions between functional constipation and functional non-retentive fecal incontinence are accurately made with a thorough clinical history and physical examination.
(3) On physical examination at least one rectal digital examination to assess fecal impaction should be performed, except in those children too frightened to undergo this examination.

(4) Children with functional non-retentive fecal incontinence are recognized by a normal defecation pattern without a fecal mass on physical examination in combination with a normal colonic transit time.

(5) A high percentage of relapse and the persistence of constipation into adulthood stress the importance of follow-up of children with constipation with or without fecal incontinence.

\section{References}

1 Di Lorenzo C, Benninga MA: Pathophysiology of pediatric fecal incontinence. Gastroenterology 2004;126(suppl):33-40.

2 Bellman M: Studies on encopresis. Acta Paediatr Scand 1966;Suppl 170:7-151.

- 3 Voskuijl WP, Heijmans J, Heijmans HS, et al: Use of Rome II criteria in childhood defecation disorders: applicability in clinical and research practice. J Pediatr 2004;145:213217.

-4 Rasquin-Weber A, Hyman PE, Cucchiara S, et al: Childhood functional gastrointestinal disorders. Gut 1999;45:60-68.

5 Loening-Baucke V: Functional fecal retention with encopresis in childhood. J Pediatr Gastroenterol Nutr 2004;38:79-84.

-6 Rasquin A, Di Lorenzo C, Forbes D, et al: Childhood functional gastrointestinal disorders: child/adolescent. Gastroenterology 2006;130:1527-1537.

7 Van den Berg MM, Benninga MA, Di Lorenzo C: Epidemiology of childhood constipation: a systematic review. Am J Gastroenterol 2006;101:2401-2409.

8 Roma-Giannikou E, Adamidis D, Gianniou $\mathrm{M}$, et al: Epidemiology of chronic constipation in Greek children. Hell J Gastroenterol 1999;12:58-62.

-9 Araujo Sant'Anna AM, Calcado AC: Constipation in school-aged children at public schools in Rio de Janeiro, Brazil. J Pediatr Gastroenterol Nutr 1999;29:190-193.

10 Rutter M, Tizard J, Yule W, et al: Research report: Isle of Wight Studies, 1964-1974. Psychol Med 1976;6:313-332.

11 Levine MD: Children with encopresis: a descriptive analysis. Pediatrics 1975;56:412416.

12 Loening-Baucke V: Encopresis and soiling. Pediatr Clin North Am 1996;43:279-298.

$\checkmark 13$ van der Wal MF, Benninga MA, Hirasing RA: The prevalence of encopresis in a multicultural population. J Pediatr Gastroenterol Nutr 2005;40:345-348.
14 Huschka M: The child's response to coercive bowel training. Psychosom Med 1942;4:301308.

15 Borowitz SM, Cox DJ, Tam A, et al: Precipitants of constipation during early childhood. J Am Board Fam Pract 2003;16:213-218.

16 Mertz H, Naliboff B, Mayer E: Physiology of refractory chronic constipation. Am J Gastroenterol 1999;94:609-615.

17 Voskuijl WP, van Ginkel R, Benninga MA, et al: New insight into rectal function in pediatric defecation disorders: disturbed rectal compliance is an essential mechanism in pediatric constipation. J Pediatr 2006; 148:6267.

18 Bongers ME, Tabbers MM, Benninga MA: Functional nonretentive fecal incontinence in children. J Pediatr Gastroenterol Nutr 2007;44:5-13.

19 Bemporad JR, Kresch RA, Asnes R, Wilson A: Chronic neurotic encopresis as a paradigm of a multifactorial psychiatric disorder. J Nerv Ment Dis 1978;166:472-479.

-20 Hoag JM, Norriss NG, Himeno ET, Jacobs J: The encopretic child and his family. J Am Acad Child Psychiatry 1971;10:242-256.

21 Gabel S, Hegedus AM, Wald A, et al: Prevalence of behavior problems and mental health utilization among encopretic children: implications for behavioral pediatrics. J Dev Behav Pediatr 1986;7:293-297.

22 Joinson C, Heron J, Butler U, Von Gontard A: Psychological differences between children with and without soiling problems. Pediatrics 2006;117:1575-1584.

23 Levine MD, Mazonson P, Bakow H: Behavioral symptom substitution in children cured of encopresis. Am J Dis Child 1980;134:663667.

24 Young MH: Functional encopresis: symptom reduction and behavioral improvement. J Dev Behav Pediatr 1995;16:226-232.
25 van der Plas RN, Benninga MA, Redekop WK, et al: Randomised trial of biofeedback training for encopresis. Arch Dis Child 1996; 75:367-374.

26 Benninga MA, Voskuijl WP, Taminiau JA: Childhood constipation: is there new light in the tunnel? J Pediatr Gastroenterol Nutr 2004;39:448-464.

27 Hatch TF: Encopresis and constipation in children. Pediatr Clin North Am 1988;35: 257-280.

28 Benninga MA, Buller HA, Heymans HS, et al: Is encopresis always the result of constipation? Arch Dis Child 1994;71:186-193.

29 van Ginkel R, Benninga MA, Blommaart PJ, et al: Lack of benefit of laxatives as adjunctive therapy for functional nonretentive fecal soiling in children. J Pediatr 2000;137:808813.

30 Loening-Baucke V: Urinary incontinence and urinary tract infection and their resolution with treatment of chronic constipation of childhood. Pediatrics 1997;100:228-232.

31 Pierce AM: Anal fissures and anal scars in anal abuse - are they significant? Pediatr Surg Int 2004;20:334-338.

32 Bruni M: Anal findings in sexual abuse of children (a descriptive study). J Forensic Sci 2003;48:1343-1346.

-33 Reuchlin-Vroklage LM, Bierma-Zeinstra S, Benninga MA, Berger MY: Diagnostic value of abdominal radiography in constipated children: a systematic review. Arch Pediatr Adolesc Med 2005;159:671-678.

-34 Bouchoucha M, Devroede G, Arhan P, et al: What is the meaning of colorectal transit time measurement? Dis Colon Rectum 1992; 35:773-782.

-35 de Lorijn F, van Wijk MP, Reitsma JB, et al: Prognosis of constipation: clinical factors and colonic transit time. Arch Dis Child 2004;89:723-727.

- 36 Benninga MA, Buller HA, Heymans HS, et al: Is encopresis always the result of constipation? Arch Dis Child 1994;71:186-193. 
>37 Papadopoulou A, Clayden GS, Booth IW: The clinical value of solid marker transit studies in childhood constipation and soiling. Eur J Pediatr 1994;153:560-564.

-38 van der Plas RN, Benninga MA, Redekop $\mathrm{WK}$, et al: How accurate is the recall of bowel habits in children with defaecation disorders? Eur J Pediatr 1997;156:178-181.

-39 Rossi A, Biancheri R, Cama A, et al: Imaging in spine and spinal cord malformations. Eur J Radiol 2004;50:177-200.

-40 Rosen R, Buonomo C, Andrade R, Nurko S: Incidence of spinal cord lesions in patients with intractable constipation. J Pediatr 2004; 145:409-411.

-41 de Lorijn F, Reitsma JB, Voskuijl WP, et al: Diagnosis of Hirschsprung's disease: a prospective, comparative accuracy study of common tests. J Pediatr 2005;146:787-792.

-42 van der Plas RN, Benninga MA, Buller HA, et al: Biofeedback training in treatment of childhood constipation: a randomised controlled study. Lancet 1996;348:776-780.

-43 Sunic-Omejc M, Mihanovic M, Bilic A, et al: Efficiency of biofeedback therapy for chronic constipation in children. Coll Antropol 2002;26(suppl):93-101.
-44 Molnar D, Taitz LS, Urwin OM, Wales JK: Anorectal manometry results in defecation disorders. Arch Dis Child 1983;58:257-261.

45 Meunier P, Marechal JM, de Beaujeu MJ: Rectoanal pressures and rectal sensitivity studies in chronic childhood constipation. Gastroenterology 1979;77:330-336.

46 Camilleri M: Testing the sensitivity hypothesis in practice: tools and methods, assumptions and pitfalls. Gut 2002;51(suppl 1):i34i40.

47 Constipation Guideline Committee of the North American Society for Pediatric Gastroenterology, Hepatology and Nutrition: Evaluation and treatment of constipation in infants and children: recommendations of the North American Society for Pediatric Gastroenterology, Hepatology and Nutrition. J Pediatr Gastroenterol Nutr 2006;43: e1-e13.

48 Voskuijl WP, Reitsma JB, van GR, et al: Longitudinal follow-up of children with functional nonretentive fecal incontinence. Clin Gastroenterol Hepatol 2006;4:67-72.

49 Voskuijl WP, van Ginkel R, Taminiau JA, et al: Loperamide suppositories in an adolescent with childhood-onset functional nonretentive fecal soiling. J Pediatr Gastroenterol Nutr 2003;37:198-200.
50 Staiano A, Andreotti MR, Greco L, et al: Long-term follow-up of children with chronic idiopathic constipation. Dig Dis Sci 1994; 39:561-564.

51 Keuzenkamp-Jansen CW, Fijnvandraat CJ, Kneepkens CM, Douwes AC: Diagnostic dilemmas and results of treatment for chronic constipation. Arch Dis Child 1996;75:3641.

52 van Ginkel R, Reitsma JB, Buller HA, et al: Childhood constipation: Longitudinal follow-up beyond puberty. Gastroenterology 2003;125:357-363.

53 Youssef NN, Langseder AL, Verga BJ, et al: Chronic childhood constipation is associated with impaired quality of life: a case-controlled study. J Pediatr Gastroenterol Nutr 2005;41:56-60.

54 Faleiros FT, Machado NC: Assessment of health-related quality of life in children with functional defecation disorders. J Pediatr (Rio J) 2006;82:421-425.

55 Khan S, Campo J, Bridge JA, et al: Long-term outcome of functional childhood constipation. Dig Dis Sci 2006;52:64-69. 